\title{
The dipeptidyl peptidase-4 inhibitor may improve the insulin secretion in type 2 diabetes patients just after starting hemodialysis treatment: preliminary study
}

Shinya Kawamoto*, Ryo Koda, Yuji Imanishi, Atsunori Yoshino and Tetsuro Takeda

\begin{abstract}
Background: Dipeptidyl peptidase-4 inhibitors (DPP-4i) have become widely used in hemodialysis patients with type 2 diabetes mellitus (T2DM). This study aimed at testing the hypothesis that administration of alogliptin, a DPP-4i, soon after hemodialysis initiation improves beta cell function in hemodialysis patients with T2DM.

Methods: Patients with end-stage renal disease and T2DM $(n=10)$ not previously treated with DPP-4i (mean age, 54.2 years) were enrolled.

The study end point was the acute insulin response to glucose assessed by a frequently sampled intravenous glucose tolerance test (IVGTT) that was conducted during the hemodialysis session just before lunch using an external circulation circuit. All patients received $6.25 \mathrm{mg}$ alogliptin for 2 weeks.

Blood glucose (Glu), serum insulin (IRI), and C-peptide (CPR) were measured before (0 min) in addition to 5 and 15 min after the glucose load. Glucagon-like peptide-1 (GLP-1) was measured before the glucose load.

Results: Glu(0) significantly decreased after the 2-week DPP-4i treatment ( $174 \pm 20 \mathrm{vs} .150 \pm 27 \mathrm{mg} / \mathrm{dL}, P=0.023)$. IRI(5) significantly increased after the DPP-4i treatment ( $14.6 \pm 31.7$ vs. $23.4 \pm 16.6 \mu \mathrm{U} / \mathrm{mL}, P=0.038)$, but IRI(0) and IRI(15) did not change significantly. GLP-1 also significantly increased after the DPP-4i treatment (6.6 \pm 4.4 vs. $2.6 \pm 0$. $8 \mathrm{pmol} / \mathrm{L}, P=0.012$ ).

Conclusions: Inhibition of DPP-4 with alogliptin improved endogenous insulin secretion in response to intravenous glucose in hemodialysis patients with T2DM.
\end{abstract}

Keywords: Diabetes mellitus, DPP-4 inhibitor, Beta cell function, Hemodialysis, GLP-1

\section{Background}

Glycemic control is reported to still be important for dialysis patients with type 2 diabetes (T2DM) to prevent large vessel complications, such as myocardial infarction, cerebral infarction, and peripheral artery disease, in addition to improving survival prognosis, although their morbidity in end-stage kidney renal disease is related to small vessel complications $[1,2]$.

However, the use of oral antidiabetic drugs is typically restricted in these patients owing to critical side effects, such as hypoglycemia and lactic acidosis, and there have been few other treatment options besides insulin, which can be difficult for the elderly or visually handicapped patients to manage because of the need for self-injection. Dipeptidyl peptidase-4 inhibitor (DPP-4i), which is a developed oral antidiabetic drug that does not require injection, has become widely used after its reported efficacy and safety in hemodialysis (HD) patients [3, 4].

This study aimed at evaluating the influence of DPP-4i on insulin secretory function and the possibility that DPP-4i can take the place of insulin in HD patients with T2DM.

* Correspondence: kwmt@dokkyomed.ac.jp

Department of Nephrology, Dokkyo Medical University Koshigaya Hospital,

2-1-50 Minamikoshigaya, Koshigaya, Saitama 343-8555, Japan 


\section{Methods}

\section{Patients}

Ten patients with end-stage renal disease and diabetes (3 women, 7 men) undergoing maintenance $\mathrm{HD}$ as inpatients at the Dokkyo Medical University Koshigaya Hospital (Koshigaya, Saitama, Japan) participated in this study between April 2012 and March 2014. All patients provided informed consent, and the study was approved by the Dokkyo Medical University Koshigaya Hospital Ethics Committee (2012/1302).

Characteristics of the patients are demonstrated in Table 1 . The mean age was $54.2 \pm 10.2$ years, and the mean HbA1c was $5.7 \% \pm 0.6 \%$ (Table 1). The mean urea nitrogen (UN) just before HD was $57 \pm 29 \mathrm{mg} / \mathrm{dL}$, mean creatinine $(\mathrm{Cr})$ was $8.0 \pm 3.6 \mathrm{mg} / \mathrm{dL}$, and mean hemoglobin $(\mathrm{Hb})$ was $8.5 \pm 1.9 \mathrm{~g} / \mathrm{dL}$. Prior to this study, seven patients were not receiving any antidiabetic treatment. Three of the patients with previous antidiabetic treatment participated in this study on the day after stopping their antidiabetic treatment without rescue therapy, for ethical reasons. All ten patients underwent $3 \mathrm{~h}$ of

Table 1 Baseline characteristics of patients $(n=10)$

\begin{tabular}{|c|c|}
\hline Characteristics & Values \\
\hline Age (years; mean $\pm S D$ ) & $54.2 \pm 10.2$ \\
\hline Gender (male/female) & $7 / 3$ \\
\hline $\mathrm{BMI}($ mean $\pm \mathrm{SD})$ & $23.7 \pm 5.1$ \\
\hline $\mathrm{BP}(\mathrm{mmHg} / \mathrm{mean} \pm \mathrm{SD})$ & $158 \pm 21 / 85 \pm 14$ \\
\hline Diabetic duration (years; mean \pm SD) & $11.2 \pm 7.9$ \\
\hline Admission reason & HD initiation (all 10 patients) \\
\hline $\mathrm{Hb}(\mathrm{g} / \mathrm{dL})$ & $8.5 \pm 1.9$ \\
\hline Alb $(g / d L)$ & $2.7 \pm 0.38$ \\
\hline $\mathrm{HbA} 1 \mathrm{c}(\% ;$ mean $\pm \mathrm{SD})$ & $5.7 \pm 0.6$ \\
\hline Glycated albumin $(G A)(\%$; mean $\pm S D)$ & $17.4 \pm 3.5$ \\
\hline Fasting plasma glucose (mg/dl; mean \pm SD) & $117 \pm 22$ \\
\hline Postprandial plasma glucose & $172 \pm 20$ \\
\hline Pre-HD plasma glucose & $184 \pm 14$ \\
\hline Previous anti-diabetic agent & $\begin{array}{l}\text { (-): } 7 \text {, alpha } \mathrm{Gl}: 1, \mathrm{aGl}+ \\
\text { mitiglinide: } 1 \text {, insulin:1 }\end{array}$ \\
\hline Dialysate & $\begin{array}{l}\text { Kindary 2E (glucose: } \\
100 \text { mg/dl) }\end{array}$ \\
\hline Dialyser & $\begin{array}{l}\text { Polysulfone (PS): } 8, \\
\text { cellulose triacetate(CTA): } 2\end{array}$ \\
\hline HD time & $3 h$ \\
\hline Quantity of blood (QB: ml/m) & $146 \pm 11$ \\
\hline Quantity of dialysate (QD: ml/m) & 500 \\
\hline KTN & $0.73 \pm 0.24$ \\
\hline Vitamin D treatment & $(+): 3,(-): 7$ \\
\hline Residual kidney function & $\begin{array}{l}\text { Urine volume } 888 \pm 461 \\
(\text { pre }) \rightarrow 519 \pm 185 \text { (post) }\end{array}$ \\
\hline Glycosuria & $( \pm): 2(+): 5(2+): 3$ \\
\hline
\end{tabular}

HD using Kindaly 2E dialysate (glucose, $100 \mathrm{mg} / \mathrm{dL}$ ). The dialyzer membrane was composed of polysulfone in eight patients and cellulose triacetate in two patients. The KT/V was $0.73 \pm 0.24$, which was not high because of the early HD initiation.

\section{Glucose tolerance test and measurements}

HD commenced at approximately 9 a.m. following a breakfast at 8 a.m., and the IVGTT was conducted during the HD session at approximately 11 a.m., based on the simple method by Gondo et al. [5]; the patients did not consume any food after breakfast. Ten grams of glucose was administered intravenously over $1 \mathrm{~min}$ during the hemodialysis session using an external circulation circuit. Blood glucose (Glu), serum insulin (IRI), and $\mathrm{C}$-peptide (CPR) were measured at the time before (0), 5, and 15 min after glucose load. IRI and CPR levels were determined using an immune-reactive method (SRL Inc., Tokyo, Japan). Glucagon-like peptide-1 (GLP1) levels at $0 \mathrm{~min}$ were determined with an enzymelinked immunosorbent assay (ELISA) (SRL Inc., Tokyo, Japan) using blood that was collected in $\mathrm{BD}^{\mathrm{\tau m}} \mathrm{P} 700$ blood collection tubes containing a proprietary DPP-4i (BD, New Jersey, USA).

After this test, they received alogliptin benzoate (DPP-4i) once daily. Dosage of alogliptin was reduced to $6.25 \mathrm{mg}$ for dialysis patients. Two weeks after alogliptin administration, they underwent the same intravenous glucose tolerance test after breakfast while undergoing alogliptin treatment.

Because of the strong reported correlation between endogenous insulin secretion and $5^{\prime} \Delta \mathrm{IRI}$ on a non-dialysis morning [5], endogenous insulin secretory function was evaluated as $5^{\prime} \Delta \mathrm{IRI}[\operatorname{IRI}(5)-\operatorname{IRI}(0)]$, to compare function before and after alogliptin administration.

\section{Statistical analyses}

Statistical analysis was performed using SPSS version 17.0 (SPSS Inc, Chicago, IL, USA). All of the results are expressed as mean and standard error of the mean. To measure differences between the two groups, paired $t$ tests were conducted. Correlation between two groups was determined using Pearson's correlation coefficient. All tests were two-tailed, and the significance was set at $P<0.05$.

\section{Results}

After 2 weeks of DPP-4i treatment, Glu(0) significantly decreased by $24.1 \pm 27.8 \mathrm{mg} / \mathrm{dL}(P=0.023)$ (Table 2$)$; Glu(5) and Glu(15) decreased, but not significantly. Figure 1 shows the IRI (a) and $5^{\prime} \Delta$ IRI (b) before and after DPP-4i. IRI(5) significantly increased by $8.8 \pm 11.4 \mu \mathrm{U} / \mathrm{mL}$ $(P=0.038)$; IRI(0) and IRI(15) did not change significantly. Endogenous insulin secretory function had a strong relationship with 5' $\Delta \mathrm{IRI}$, which significantly increased by 
Table 2 IVGTT before and after DPP-4i treatment $(n=10)$

\begin{tabular}{llll}
\hline & Before & After & $P$ value \\
\hline Fasting plasma glucose $(\mathrm{mg} / \mathrm{dl})$ & $117 \pm 22$ & $107 \pm 16$ & 0.33 \\
Pre-HD plasma glucose $(\mathrm{mg} / \mathrm{dl})$ & $182 \pm 15$ & $145 \pm 17$ & 0.035 \\
Glu(0) $\mathrm{mg} / \mathrm{dl}$ & $174 \pm 20$ & $150 \pm 27$ & 0.023 \\
Glu(5) & $228 \pm 32$ & $204 \pm 37$ & 0.065 \\
$\mathrm{Glu}(15)$ & $202 \pm 27$ & $182 \pm 43$ & 0.09 \\
$\mid \mathrm{RI}(0) \mu \mathrm{U} / \mathrm{ml}$ & $13.0 \pm 5.8$ & $15.4 \pm 11.1$ & 0.37 \\
$\mid \mathrm{RI}(5)$ & $14.6 \pm 6.9$ & $23.4 \pm 16.6$ & 0.038 \\
$\mid \mathrm{RI}(15)$ & $15.7 \pm 7.8$ & $19.6 \pm 14.6$ & 0.258 \\
$5^{\prime} \Delta \mid \mathrm{RI}$ & $1.61 \pm 1.87$ & $8.04 \pm 8.07$ & 0.015 \\
$15^{\prime} \Delta \mid \mathrm{RI}$ & $2.63 \pm 2.75$ & $4.24 \pm 4.64$ & 0.268 \\
0.268 & $6.4 \pm 2.9$ & $5.7 \pm 2.9$ & 0.408 \\
$\mathrm{CPR}(5)$ & $6.1 \pm 2.4$ & $6.1 \pm 2.8$ & 0.976 \\
$\mathrm{CPR}(15)$ & $6.1 \pm 2.4$ & $6.1 \pm 2.8$ & 0.918 \\
$\mathrm{GLP}-1 \mathrm{pmol} / \mathrm{L}$ & $2.64 \pm 0.76$ & $6.63 \pm 4.42$ & 0.012 \\
\hline
\end{tabular}

$6.43 \pm 6.72 \mathrm{U} / \mathrm{mL}(P=0.014)$. CPR did not change significantly at any time. GLP-1 also significantly increased by $3.85 \pm 3.85 \mathrm{nmol} / \mathrm{nL}(P=0.012)$.

\section{Discussion}

In this study, $5^{\prime} \Delta \mathrm{IRI}$, which had strong relationship with endogenous insulin secretory function [5], and GLP-1 were significantly increased after the DPP-4i treatment on patients in the initial phase of the dialysis. Acute insulin secretory response by IVGTT is to calm down within $10 \mathrm{~min}$, but the strength of the response is strongly associated with the increase rate in glucose-byglucose load not only the glucose level itself [6]. Therefore, evaluation of endogenous insulin secretory function by IVGTT performed before lunch when glucose level showed close to normal but not complete fasting such as in the morning is considered to be no problem, which Gondo mentioned [5].

Our study has several limitations, such as the small number of patients and performed in the incident hemodialysis inpatients. In this phase, uremia, anemia, malnutrition, CKD-MBD, and acidosis affect impaired glucose metabolism. Our studies were performed on patients who already had some sessions of HD and whose appetite was recovered presenting high postprandial plasma glucose. But it was not a stable state such as the maintenance of hemodialysis patients. In fact, urine volume at first IVGTT was significantly more than that at second IVGTT. We did not evaluate the exact residual kidney function, but considering the data of urine volume and urine sugar qualitative testing at two points, the differences in glycosuria between the two points was considered to have no effect on impaired glucose metabolism. We also evaluated the influence of the initial phase of the dialysis on glucose metabolism between the two points in patients without DPP4i as control. There was no remarkable difference in $5^{\prime} \Delta$ IRI between the two points, and we think that the influence of the initial phase of the dialysis was considered as no great impact on our results.

Active vitamin $D$ administration improves insulin secretion from $\beta$ cell in uremia. In our patients, three patients used VDRA, but there was no patient who started VDRA during our study. So even if our study was performed in the HD initial phase, these effects were considered to be minimal.

Incretin is produced by the gastrointestinal tract following stimulation by the nutrients (e.g., glucose, other carbohydrates, triglycerides, proteins) from a meal. It enhances the glucose-dependent secretion of insulin from beta cells, promotes beta cell proliferation, and inhibits beta cell apoptosis [7, 8]. Incretin

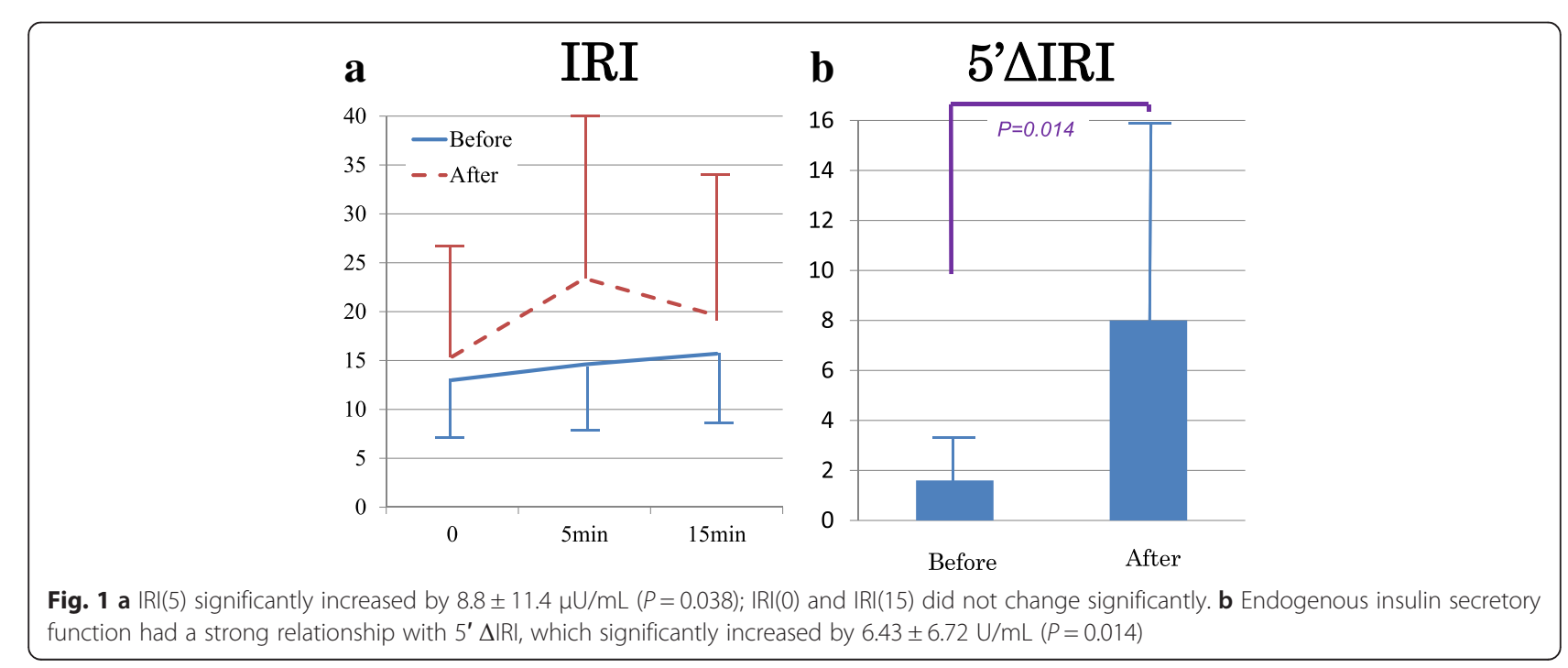


hormones are not released with the intravenous administration of glucose [9-11]. Therefore, oral glucose elicits a higher insulin secretory response than intravenous glucose, even for the same amount of glucose [12] or similar concentrations following a glucose load (i.e., isoglycemia) [13, 14]. This is called the incretin effect.

Insulin secretion after an intravenous glucose load is thought to be a result of released insulin particles that directly bind to the cellular membrane of pancreatic beta cells. The rapid insulin release is gradually augmented with increasing GLP-1 [15].

Because of the incretin effect, we conducted an IVGTT, rather than an oral glucose tolerance test, via an external circulation circuit, which also eliminated the need for multiple punctures for glucose infusion and blood sampling. Although an intravenous glucose load is thought to have less effect on incretin and insulin secretion than an oral glucose load, both Glu and insulin secretion significantly improved after DPP-4i treatment in the present study.

Incretin is rapidly degraded by DPP-4. Therefore, DPP-4i enhances the effect of insulin by controlling the degradation of incretin. In the present study, GLP-1 levels significantly increased after DPP-4i treatment, even in the fasting state. The improvement in endogenous insulin secretion following the 2-week DPP-4i treatment in this study could be a result of the effect of the elevated GLP-1 levels on the rapid increase of insulin. Owing to the small sample size, there was likely insufficient power for a significant correlation between $\triangle$ GLP-1 (PostGLP-1-PreGLP-1) and $\Delta 5^{\prime} \Delta$ IRI (Post5 $5^{\prime} \Delta$ IRI-Pre5' $\Delta$ IRI). The lack of significant changes in CPR concentration after DPP-4i treatment could also be explained by this rapid phase of insulin release with IVGTT.

Valdarli et al. reported that DPP-4 inhibition augmented insulin secretory responses both after oral glucose and during isoglycemic intravenous glucose infusions, with no net change in incretin effect, and that DPP-4i induced changes in the incretin-related environment of islets that may persist overnight [16].

DPP-4i also inhibits glucagon release, leading to enhanced suppression of endogenous glucose production [17]. Glucagon concentrations are suppressed with both oral and intravenous glucose, although this occurs earlier with intravenous glucose $[18,19]$. In the present study, we did not measure glucagon; therefore, we could not determine if glucagon concentration was suppressed in the early phase of IVGTT. This is certainly a limitation of our study, and it deserves future research.

The inhibition by DPP-4 was associated with significant increases in meal-stimulated plasma-active GLP-1 levels, which remained elevated from breakfast to just before lunch, when the measurements were taken, without returning to baseline levels.

In actual conditions, ingested food may stimulate incretin secretion by the gastrointestinal tract, which then enhances insulin secretion from the beta cells, and this may have an additive effect on the improvement in glucose homeostasis observed in the present study with HD patients with T2DM. Our results also support the usefulness of DPP4i in HD patients by the improvement of $\beta$ cell function. It could be one of the causes that HD patients could withdraw from insulin treatment or decrease the amount of insulin by DPP4i.

\section{Conclusions}

DPP-4i (alogliptin) treatment resulted in improvements in the endogenous insulin secretory function of HD patients with T2DM, primarily owing to an augmentation of the insulin secretory response, even with intravenous administration of glucose.

\section{Disclosure of grants or other funding}

This study was not supported by any grants or funding.

\section{Authors' contributions}

$\mathrm{RK}, \mathrm{YI}$, and $\mathrm{AY}$ participated in the patient selection and performing IVGTT. TT conceived the study, participated in the study design and coordination, and helped to draft the manuscript. All authors read approved the final manuscript.

\section{Competing interests}

The authors declare that they have no competing interests.

Received: 18 October 2015 Accepted: 13 May 2016

Published online: 04 July 2016

\section{References}

1. Shima K, Komatsu M, Kuwahara K, Minaguchi J, Kawashima S. Stringent glycemic control prolongs survival in diabetic patients with end-stage renal disease on hemodialysis. Nephrology. 2010;15:632-8.

2. Ricks J, Molnar MZ, Kovesdy CP, Shal A, Nissenson AR, Williams M, et al. Glycemic control and cardiovascular mortality in hemodialysis patients with diabetes: a 6-year cohort study. Diabetes. 2012;61:708-15.

3. Nakamura Y, Shimizu T, Fujita K, Inoue M, Gotoh H, Gotoh Y, et al. Effects of alogliptin benzoate in hemodialysis patients with diabetes. J Jpn Soc Dial Ther. 2012;45(1):49-57

4. Ishioka K, Furuya R, Iwagami M, Tsutsumi D, Mochida Y, Oka M, et al. Vildagliptin improves glycemic control in type 2 diabetes patients undergoing hemodialysis. J Jpn Soc Dial Ther. 2013;46(1):103-10.

5. Gondo A, Matsumoto H, Okada T, Nagaoka Y, Yoshino M, Tomaru R, et al. A simple method of evaluationg endogenous insulin secretory function durinjg hemodialysis session. J Jpn Soc Dial Ther. 2008;41(3):187-93.

6. Cobelli C, Toffolo GM, Dalla Man C, Campioni M, Denti P, Caumo A, et al. Assessment of $\beta$-cell function in humans, simultaneously with insulin sensitivity and hepatic extraction from intravenous and oral glucose tests. Am J Physiol Endocrinol Metab. 2007;293:E1-15.

7. D'Allesio DA, Kahn SE, LEusner CR, Ensinck JW. Glucagon-like-peptide 1 enhances glucose tolerance both by stimulation of insulin release and by increasing insulin-independent glucose disposal. J Clin Invest. 1994;93:2263-6.

8. Doyle ME, Egan JM. Glucagon-like peptide-1. Recent Prog Horm Res. 2001;56:377-99.

9. Orskov C, Rabenhoj L, Wettergren A, Kofod H, Holst JJ. Tissue and plasma concentration of amidated and glycin-extended glucagon-like peptide 1 in humans. Diabetes. 1994;43:535-9.

10. Orskov C, Wettergren A, Holst JJ. Secretion of the incretin hormones glucagon-like peptide 1 and gastric inhibitory polypeptide correlates with 
insulin secretion in normal man throughout the day. Scand J Gastroenterol. 1996;31:665-70.

11. Nauck MA, El-Ouaghlidi A, Gabrys B, Hucking K, Holst JJ, Deacon CF, et al. Secretion of incretin hormones (GIP And GLP-1) and incretin effect after oral glucose in first-degree relatives of patients with type 2 diabetes. Regul Pept. 2004;122:209-17.

12. Tillil H, Shapiro ET, Miller MA, Karrison T, Frank BH, Gallway JA, et al. Dosedependent effects of oral and intravenous glucose on insulin secretion and clearance in normal humans. Am J Physiol. 1988;254:E349-57.

13. Nauck MA, Homberger E, Siegel EG, Allen RC, Eaton RP, Ebert R, et al. Incretin effects of increasing glucose loads in man calculated from venous insulin and C-peptide responses. J Clin Endocrinol Metab. 1986;63:492-8.

14. Nauck M, Stockmann F, Ebert R, Creutzfeldt W. Reduced incretin effect in type 2 (non-insulin-dependent) diabetes. Diabetologia. 1986;29:46-52.

15. Chan HM, Jain R, Ahren B, Pacini G, D'Ageni DZ. Effects of increasing doses of glucagon-like peptide-1 on insulin-releasing phases during intravenous glucose administration in mice. Am J Physiol Regul Integr Comp Physiol. 2011;300(5):R1126-33.

16. Valdarli I, Nauck MA, Köthe LD, Deacon CF, Holst JJ, Schweizer A, et al. Inhibition of DPP-4 with vildagliptin improved insulin secretion in response to oral as well as "isoglycemic" intravenous glucose without numerically changing the incretin effect in patients with type 2 diabetes. J Clin Endocrinol Metab. 2011;96(4):945-54.

17. Balas B, Baig MR, Watson C, Dunning BE, Ligueros-Sayla M, Wang Y, et al. The dipeptidyl peptidase IV inhibitor vildagliptin suppresses endogenous glucose production and enhances islet function after single-dose administration in type 2 diabetic patients. J Clin Endocrinol Metab. 2007;92(4):1249-55.

18. Knop FK, Vilsboll T, Madsbad S, Holst JJ, Krarup T. Inappropriate suppression of glucagon during OGTT but not during isoglycemic i.v. glucose infusion contributes to the reduced incretin effect in type 2 diabetes mellitus. Diabetologia. 2007;50:797-805.

19. Meier JJ, Deacon CF, Schmidt WE, Holst JJ, Nauck MA. Suppression of glucagon secretion is lower after oral glucose administration than during intravenous glucose administration in human subjects. Diabetologia. 2007;50:806-13.

\section{Submit your next manuscript to BioMed Central and we will help you at every step:}

- We accept pre-submission inquiries

- Our selector tool helps you to find the most relevant journal

- We provide round the clock customer support

- Convenient online submission

- Thorough peer review

- Inclusion in PubMed and all major indexing services

- Maximum visibility for your research

Submit your manuscript at www.biomedcentral.com/submit 